\title{
Potential short-term use of oral cladribine in treatment of relapsing-remitting multiple sclerosis
}

\author{
This article was published in the following Dove Press journal: \\ Neuropsychiatric Disease and Treatment \\ 15 September 2010 \\ Number of times this article has been viewed
}

\author{
Julie A Murphy \\ Jacklyn A Harris \\ Andrew J Crannage \\ St Louis College of Pharmacy, \\ St Louis, MO, USA
}

Correspondence: Julie A Murphy Department of Pharmacy Practice, St Louis College of Pharmacy, 4588 Parkview Place, St Louis, MO 63। I0-1088, USA

Tel + I 3144468504

Fax + I 314 4468500

Email jmurphy@stlcop.edu

\begin{abstract}
Multiple sclerosis (MS) is a chronic, immune-mediated disorder of the central nervous system. The clinical course of MS varies among patients. Currently, interferon (IFN) products, including IFN $\beta$-1a administered intramuscularly or subcutaneously and IFN $\beta-1 \mathrm{~b}$ subcutaneously, glatiramer acetate, natalizumab, and mitoxantrone are approved diseasemodifying therapies for the treatment of relapsing-remitting MS. Cladribine, also known as 2-chlorodeoxyadenosine, is a synthetic adenosine deaminase-resistant purine nucleoside analog that preferentially depletes lymphocyte subpopulations. This sustained effect on lymphocytes is advantageous for patients with MS. CLARITY (CLAdRIbine Tablets Treating MS OrallY), a Phase III trial, has demonstrated that short-term oral cladribine decreases relapse rates and risk of disability progression in comparison with placebo. Cladribine was well tolerated in the study, with the most common adverse effects being headache, nausea, upper respiratory tract infections, and lymphocytopenia. An ongoing study is evaluating the efficacy and safety of the combination of oral cladribine and IFN- $\beta$ products. A further ongoing study is examining the use of oral cladribine in clinically isolated syndrome and time to conversion to MS. Although the results of CLARITY are promising, the exact role of oral cladribine may be better defined with the completion of ongoing studies.
\end{abstract}

Keywords: cladribine, multiple sclerosis, relapsing-remitting, oral, disease-modifying therapy

\section{Introduction}

Multiple sclerosis (MS) is a chronic, immune-mediated disorder of the central nervous system. More than 400,000 Americans and 2.7 million people worldwide have been diagnosed with MS. ${ }^{1}$ MS more commonly affects women by a ratio of 2:1 over men, and $80 \%$ of patients will be diagnosed at $16-45$ years of age. ${ }^{1}$ The clinical course of MS varies between patients, is characterized by relapses and remissions, and may be categorized on the basis of the pattern of these episodes. The clinical categories of MS include progressive relapsing (PRMS) and relapsing-remitting (RRMS), which may eventually become chronic and progressive MS. Chronic and progressive MS can be further subdivided into secondary progressive MS and primary progressive MS. ${ }^{2}$

Currently, interferon (IFN) $\beta$-1a intramuscularly (Avonex ${ }^{\circledR}$ ), IFN $\beta$-1a subcutaneously $\left(\right.$ Rebif $\left.^{\circledR}\right)$, IFN $\beta$-1b subcutaneously $\left(\right.$ Betaseron $^{\circledR}$ ), glatiramer acetate $\left(\right.$ Copaxone ${ }^{\circledR}$ ), natalizumab (Tysabri ${ }^{\circledR}$ ), and mitoxantrone (Novantrone ${ }^{\circledR}$ ) are approved diseasemodifying therapies (DMTs) for the treatment of RRMS. The immunomodulatory interferons (IFNs) and glatiramer, are considered first-line agents, whereas natalizumab, an immunosuppressive agent, is considered second-line. Mitoxantrone is indicated for the treatment of secondary progressive MS, PRMS, and RRMS. Although it should not 
be used early in the course of disease due to its toxicity profile (ie, cardiotoxicity, leukemia), delaying treatment should be avoided because of the risk of clinical deterioration. ${ }^{3}$

Three trials have demonstrated the efficacy of the IFNs in comparison with placebo. The IFNB Multiple Sclerosis Study Group compared 1.6 MIU of IFN $\beta$-1b, 8 MIU of IFN $\beta-1 b$, and placebo administered subcutaneously every other day. ${ }^{4}$ Annual relapse rates were $1.17(P=0.01$ versus placebo), 0.84 ( $P=0.0001$ versus placebo), and 1.27, respectively. The percentage of subjects who were relapse-free after two years was $18.4 \%, 29 \%$ ( $P=0.007$ versus placebo), and $14.6 \%$, respectively. For RRMS subjects who received IFN $\beta$-1a subcutaneously three times weekly, the PRISMS (Prevention of Relapses and Disability by Interferon beta-1a Subcutaneously in Multiple Sclerosis) study group found both a decreased frequency of relapses over two years (risk reductions $27 \%$, 95\% confidence interval [CI]: 14\%-39\% and $33 \%, 95 \% \mathrm{CI}: 21 \%-44 \%$, for the $22 \mu \mathrm{g}$ and $44 \mu \mathrm{g}$ groups, respectively) and a delayed accumulation of physical disability. ${ }^{5}$ The burden of disease, measured with magnetic resonance imaging, showed a progressive increase of $10.9 \%$, a $1.2 \%$ decrease, and a $3.8 \%$ decrease for the placebo, $22 \mu \mathrm{g}$, and $44 \mu \mathrm{g}$ groups, respectively $(P<0.0001$ compared with placebo for both doses). The CHAMPS (Controlled High Risk Avonex Multiple Sclerosis Study) investigators found a relative reduction in brain lesion volume at 18 months in subjects with an acute demyelinating event who received 30 $\mu \mathrm{g}$ of IFN $\beta$-1a intramuscularly weekly $(P<0.001) .{ }^{6}$ The cumulative probability of subjects developing clinically definite MS over a three-year follow-up period was lower in the IFN $\beta$-1a group compared with placebo $(0.56,95 \% \mathrm{CI}$ : 0.38-0.81, $P=0.002$ ).

A few studies have attempted to determine the impact of varying IFN dosage regimens on RRMS. The EVIDENCE (Evidence for Interferon Dose-Response: European-North American Comparative Efficacy) trial demonstrated that after 24 weeks $74.9 \%$ of subjects receiving IFN $\beta$ - 1 a $44 \mu \mathrm{g}$ subcutaneously three times weekly were relapse-free versus $63.3 \%$ of subjects who received IFN $\beta$-1a $30 \mu \mathrm{g}$ intramuscularly once weekly. ${ }^{7}$ The INCOMIN (Independent Comparison of Interferon) trial showed that after two years $51 \%$ of subjects receiving IFN $\beta$-1b $250 \mu \mathrm{g}$ subcutaneously every other day remained relapse-free versus $36 \%$ of subjects receiving IFN $\beta$-1a $30 \mu \mathrm{g}$ intramuscularly once weekly. ${ }^{8}$ These data suggest that IFN $\beta$ products may be more effective when dosed more frequently.

A pivotal, two-year, multicenter Phase III study has demonstrated that glatiramer, when administered as $20 \mathrm{mg}$ subcutaneously daily, reduces relapse rates by $29 \%$ compared with placebo $(P=0.007){ }^{9}$

A few studies have compared the efficacy of the IFN products with that of glatiramer, including the BEYOND (Betaferon Efficacy Yielding Outcomes of a New Dose) and REGARD (Rebif vs Glatiramer Acetate in Relapsing MS Disease) trials. The three arms of the BEYOND trial included IFN $\beta$-1b $250 \mu \mathrm{g}$ subcutaneously every other day, IFN $\beta$-1b $500 \mu \mathrm{g}$ subcutaneously every other day, and glatiramer $20 \mathrm{mg}$ subcutaneously daily. ${ }^{10}$ The BEYOND trial demonstrated no difference in annual relapse rate between glatiramer and the $250 \mu \mathrm{g}$ IFN $\beta$-1b dose (hazards ratio [HR] 1.06, 95\% CI: $0.89-1.26, P=0.73$ ) and the $500 \mu \mathrm{g}$ IFN $\beta$-1b dose (HR 0.98, 95\% CI: $0.82-1.18, P=0.43$ ). The REGARD trial compared IFN $\beta$-1a $44 \mu \mathrm{g}$ subcutaneously three times weekly with glatiramer $20 \mathrm{mg}$ subcutaneously daily. ${ }^{11}$ The REGARD trial demonstrated no difference in time to first relapse (HR 0.94, 95\% CI: $0.74-1.21, P=0.64)$. Because of their similar efficacy, any of these agents may be considered first-line for the treatment of RRMS.

Natalizumab was first approved for the treatment of RRMS based on the findings of two studies. Natalizumab reduced the relapse rate at one year by $68 \%$ versus placebo $(P<0.001)$ in the AFFIRM (Natalizumab Safety and Efficacy in Relapsing Remitting Multiple Sclerosis) study. ${ }^{12}$ The SENTINEL (Safety and Efficacy of Natalizumab in Combination with Interferon Beta-1a in Patients with Relapsing Remitting Multiple Sclerosis) study compared combination treatment with IFN $\beta$-1a plus natalizumab with IFN $\beta$-1a monotherapy. ${ }^{13}$ Combination therapy resulted in a $24 \%$ reduction in the relative risk of sustained disability progression $(P=0.02)$. Combination therapy was also associated with a lower annual relapse rate $(34 \%$ versus $75 \%, P<0.001)$. While natalizumab is effective for active forms of RRMS, it is usually reserved for patients who have inadequate responses to or are unable to tolerate firstline DMTs, because of the risk of progressive multifocal leukoencephalopathy. ${ }^{14}$

While in the studies all of the DMTs for the treatment of RRMS have proven to be effective in decreasing relapse rates, increasing the percentage of patients that are relapsefree, and/or delaying progression of disease, reports show that $7 \%-49 \%$ of RRMS patients do not have an adequate response to DMT. ${ }^{15}$ The DMTs must be administered either subcutaneously or intramuscularly, and may lead to toxicities, such as flu-like symptoms, headache, or depression with the IFN products, injection reactions with glatiramer, and multifocal leukoencephalopathy with natalizumab. These limitations led 
to the need for the development of potentially better tolerated oral treatments, such as cladribine, for RRMS.

\section{Pharmacology and pharmacokinetics}

Cladribine, also known as 2-chlorodeoxyadenosine, is a synthetic adenosine deaminase-resistant purine nucleoside ana$\log$ that preferentially depletes lymphocyte subpopulations. ${ }^{16}$ This beneficial and sustained effect on lymphocytes is advantageous for patients with MS. Cladribine is structurally similar to deoxyadenosine, with the substitution of a chlorine atom for a hydrogen atom at the two position of the purine ring. ${ }^{17}$ Cladribine is a prodrug which requires passive intracellular transport where phosphorylation to active metabolites occurs. It is phosphorylated by deoxycytidine kinase to active triphosphate deoxynucleotide. Accumulation of active triphosphate deoxynucleotide results in disrupted cellular metabolism, DNA strand breaks, interference with DNA repair, and eventual cell death. Deoxyadenosine can be deaminated to deoxyinosine by adenosine deaminase. This enzyme regulates deoxyadenosine concentrations by controlling the deamination process. However, cladribine is resistant to the effects of adenosine deaminase. Following cladribine administration, lymphocytes will accumulate high concentrations of deoxynucleotides. This accumulation is due to a high activity level of deoxycytidine kinase associated with lymphocytes. ${ }^{18}$ These characteristics of cladribine, including activation by deoxycytidine kinase and resistance to adenosine deaminase, combined with high concentrations of deoxycytidine kinase in lymphocytes, results in the unique preferential lymphocytotoxicity associated with cladribine. Also, cladribine may prevent the migration of monocytes and lymphocytes across the blood-brain barrier into the central nervous system. Cladribine has been shown to decrease the migratory capacity of $\mathrm{CD} 14^{+}$monocytes, $\mathrm{CD} 4^{+} \mathrm{T}$ lymphocytes, and $\mathrm{CD}^{+} \mathrm{T}$ lymphocytes, with greater effects on $\mathrm{T}$ lymphocytes. ${ }^{19}$

The pharmacokinetic properties of cladribine were investigated using high-performance liquid chromatography to evaluate two- and 24 -hour $0.14 \mathrm{mg} / \mathrm{kg}$ infusions. The volume of distribution was determined to be $9.2 \pm 5.4 \mathrm{~L} / \mathrm{kg}$. When using a two-compartment model, mean alpha and beta half-lives were 35 minutes and 6.7 hours, respectively. The concentration obtained 6.3 hours after the start of the two-hour infusion had decreased to the same as the steady-state concentration during the 24-hour infusion. When using a three-compartment model, mean alpha, beta, and gamma half-lives were eight minutes, one hour and six minutes, and 6.3 hours, respectively. The long gamma phase after the two-hour infusion suggests that cladribine could be administered intermittently with retained activity. ${ }^{20}$

Additional methods, including radioimmunoassay, have evaluated the pharmacokinetic properties of cladribine. The terminal half-life has been found to range from 5.7 to 19.7 hours with a volume of distribution of 54 to $357 \mathrm{~L} / \mathrm{m}^{2} .^{21}$ In patients with a healthy central nervous system, cladribine concentrations in cerebrospinal fluid are $25 \%$ that of plasma concentrations; however, in subjects with meningeal disease, cladribine concentrations in cerebrospinal fluid exceed plasma concentrations. ${ }^{21}$ The renal elimination of cladribine was evaluated in children with acute leukemia. Mean renal clearance as a percentage of total clearance was $51 \%$, with a range from $11 \%$ to $85.1 \% .^{22}$

Oral cladribine dissolved in phosphate-buffered saline revealed a mean bioavailability of $48 \pm 8 \%$ for subjects dosed with $0.14 \mathrm{mg} / \mathrm{kg}$ and $55 \pm 17 \%$ for subjects dosed with $0.28 \mathrm{mg} / \mathrm{kg} .{ }^{23} \mathrm{The}$ effects of food and proton pump inhibitors on oral cladribine administration have also been studied. ${ }^{24}$ In this study, oral bioavailability was found to be $42 \%$ with food intake and $46 \%$ while fasting, although this difference was not statistically significant. However, food intake did reduce the maximum plasma concentration by $40 \%$ and delayed time to reach maximum plasma concentration by approximately 0.8 hours. Omeprazole did not significantly affect the bioavailability of oral cladribine. Bioavailability was $51 \%$ with omeprazole treatment and $46 \%$ without treatment. Overall, oral cladribine can be taken without regard to omeprazole or food.

The mechanism of action and pharmacodynamic properties of cladribine make it unique. The preferential and sustained effects on lymphocytes render cladribine a potential short-course treatment for MS. Cladribine's long elimination half-life and acceptable bioavailability makes once-daily dosing of an oral formulation possible. Hence, cladribine has been formulated as a $10 \mathrm{mg}$ tablet for oral administration. Clinical studies are necessary to determine if these pharmacodynamic and pharmacokinetic properties can be successfully exploited for short-term oral treatment of MS.

\section{Clinical studies}

Giovannoni et al conducted CLARITY (CLAdRIbine Tablets Treating MS OrallY), a Phase III trial evaluating the safety and efficacy of oral cladribine in subjects with RRMS. ${ }^{25}$ A total of 1326 subjects were randomized in this double-blind, placebocontrolled, multicenter trial in a 1:1:1 ratio to receive cladribine $3.5 \mathrm{mg} / \mathrm{kg}$, cladribine $5.25 \mathrm{mg} / \mathrm{kg}$, or placebo. Study drugs were 
administered as short courses. A course of treatment involved administration of study drugs once daily for the first four or five days of a 28-day period. Once-daily cladribine consisted of administration of one or two $10 \mathrm{mg}$ tablets. Subjects received two courses of cladribine followed by two courses of placebo in the $3.5 \mathrm{mg} / \mathrm{kg}$ group, four courses of cladribine in the $5.25 \mathrm{mg} /$ $\mathrm{kg}$ group, or four courses of placebo during the first 48-week treatment period starting on day one and at weeks 5, 9, and 13. This resulted in patients taking cladribine tablets for 8-20 days during the first 48 weeks. Both cladribine groups received two courses of treatment during the second 48-week treatment period. Subjects in the placebo group also received two courses of placebo. This resulted in patients taking cladribine tablets for 8-10 days during the second 48 weeks. If a subject had more than one relapse episode or a sustained increase in the Kurtke Expanded Disability Status Scale (EDSS), subcutaneous IFN $\beta$-1a could be used.

The primary endpoint assessed was rate of relapse at 96 weeks. Investigators defined relapse as an increase of two points in at least one EDSS functional system or at least two functional systems with an increase of one point, which had to precede at least a month of clinical stability or improvement, in the absence of a fever.

The secondary endpoints assessing efficacy were the proportion of subjects that were relapse-free, time to sustained progression of disability, time to first relapse, and the proportion of subjects receiving IFN $\beta$-1 a rescue therapy. Sustained progression of disability was defined as a sustained increase of at least three months of at least one point in the EDSS score or an increase of 1.5 points if the baseline EDSS score was zero. The magnetic resonance imaging secondary endpoints included the mean number of lesions per subject per scan at 96 weeks for gadolinium-enhancing $\mathrm{T}_{1}$ weighted lesions, active $T_{2}$ weighted lesions, and combined unique lesions. Unique lesions were defined as new gadolinium-enhancing
$\mathrm{T}_{1}$ weighted lesions or new nonenhancing or enlarging $\mathrm{T}_{2}$ weighted lesions. Safety was assessed by incidence of treatment-emergent adverse events, physical examination, and laboratory measurements.

Investigators found a significant reduction in the annualized relapse rate at 96 weeks in both cladribine groups $(0.14$ in $3.5 \mathrm{mg} / \mathrm{kg}$ and 0.15 in $5.25 \mathrm{mg} / \mathrm{kg}$ ) compared with placebo (0.33), with relative reductions of $57.6 \%$ and $54.5 \%$, respectively $(P<0.001)$. The results for the secondary endpoints are presented in Table 1. The HR for cladribine versus placebo for the time to first relapse was 0.44 for the $3.5 \mathrm{mg} / \mathrm{kg}$ group (95\% CI: $0.34-0.58)$ and 0.46 for the $5.25 \mathrm{mg} / \mathrm{kg}$ group $(95 \%$ CI: 0.36-0.6). For the time to three-month sustained change in EDSS score, there was a relative risk reduction of $33 \%$ for the $3.5 \mathrm{mg} / \mathrm{kg}$ group (HR 0.67, 95\% CI: 0.48-0.93) and $31 \%$ for the $5.25 \mathrm{mg} / \mathrm{kg}$ group (HR 0.69, 95\% CI: 0.49-0.96) compared with placebo. Both cladribine treatment groups had significant reductions in magnetic resonance imaging activity as reported in Table 1.

Treatment-emergent adverse events are reported in Table 2. An adverse event was reported in $80.7 \%$ and $83.9 \%$ of subjects receiving cladribine $3.5 \mathrm{mg} / \mathrm{kg}$ and $5.25 \mathrm{mg} / \mathrm{kg}$, respectively, compared with $73.3 \%$ of subjects receiving placebo. Event severity was rated with mild being an event or symptom easily tolerated, moderate being an event or symptom which interferes with or reduces the usual level of activity, and severe being an event or symptom which causes substantial impairment of functioning, reduces the usual level of activity, or endangers the patient's life. The most common reported adverse event in the subjects receiving cladribine was mild or moderate lymphocytopenia. There were three reported cases of severe neutropenia in the cladribine groups, one in the $3.5 \mathrm{mg} / \mathrm{kg}$ group and two in the $5.25 \mathrm{mg} /$ $\mathrm{kg}$ group. Cladribine was discontinued due to adverse events in $3.5 \%, 7.9 \%$, and $2.1 \%$ of subjects receiving $3.5 \mathrm{mg} / \mathrm{kg}$,

Table I Secondary endpoints (intention-to-treat population)

\begin{tabular}{|c|c|c|c|c|c|}
\hline \multirow[t]{3}{*}{ Endpoint } & \multirow{3}{*}{$\begin{array}{l}\text { Placebo } \\
(n=437)\end{array}$} & \multicolumn{2}{|l|}{ Cladribine } & \multicolumn{2}{|l|}{ Cladribine } \\
\hline & & $3.5 \mathrm{mg} / \mathrm{kg}$ & $P$ value & $5.25 \mathrm{mg} / \mathrm{kg}$ & $P$ value \\
\hline & & \multicolumn{2}{|l|}{$(n=433)$} & \multicolumn{2}{|l|}{$(n=456)$} \\
\hline Patients relapse-free & 266 & 345 & $<0.001$ & 360 & $<0.001$ \\
\hline Time to sustained progression of disability (months) & 10.8 & 13.6 & 0.02 & 13.6 & 0.03 \\
\hline Time to first relapse (months) & 4.6 & 13.4 & $<0.001$ & 13.3 & $<0.001$ \\
\hline Patients requiring rescue therapy $[\mathrm{n}(\%)]$ & $27(6.2 \%)$ & II (2.5\%) & 0.01 & $9(2.0 \%)$ & 0.003 \\
\hline \multicolumn{6}{|l|}{ Magnetic resonance imaging endpoints } \\
\hline Gadolinium-enhancing $T$, weighted lesions (mean) & 0.91 & 0.12 & $<0.001$ & 0.11 & $<0.001$ \\
\hline Active $T_{2}$ weighted lesions (mean) & 1.43 & 0.38 & $<0.001$ & 0.33 & $<0.00 \mathrm{I}$ \\
\hline Combined unique lesions (mean) & 1.72 & 0.43 & $<0.001$ & 0.38 & $<0.001$ \\
\hline
\end{tabular}


Table 2 Treatment-emergent adverse events

\begin{tabular}{|c|c|c|c|c|}
\hline \multirow[t]{3}{*}{ Adverse event } & \multirow{3}{*}{$\begin{array}{l}\text { Placebo (\%) } \\
(n=435)\end{array}$} & \multicolumn{3}{|c|}{ Cladribine (\%) } \\
\hline & & $3.5 \mathrm{mg} / \mathrm{kg}$ & $\begin{array}{l}5.25 \mathrm{mg} / \\
\mathrm{kg}\end{array}$ & Combined doses \\
\hline & & $(n=430)$ & $(n=454)$ & $(n=884)$ \\
\hline \multicolumn{5}{|l|}{ Most common } \\
\hline Headache & $75(17.2)$ & $104(24.2)$ & 94 (20.7) & $198(22.4)$ \\
\hline Lymphocytopenia & $8(1.8)$ & $93(21.6)$ & $143(3 \mid .5)$ & $236(26.7)$ \\
\hline Nasopharyngitis & $56(12.9)$ & $62(14.4)$ & $58(12.8)$ & $120(13.6)$ \\
\hline Upper respiratory tract infection & $42(9.7)$ & $54(12.6)$ & $52(11.5)$ & $106(12)$ \\
\hline Nausea & $39(9)$ & $43(10)$ & $50(\mathrm{II})$ & $93(10.5)$ \\
\hline Any serious adverse event & $28(6.4)$ & $36(8.4)$ & $4 I(9)$ & $77(8.7)$ \\
\hline Infections and infestations & $7(1.6)$ & $10(2.3)$ & $13(2.9)$ & $23(2.6)$ \\
\hline Neoplasms & 0 & $6(1.4)$ & $4(0.9)$ & $10(1.1)$ \\
\hline Death & $2(0.5)$ & $2(0.5)$ & $2(0.4)$ & $4(0.5)$ \\
\hline
\end{tabular}

$5.25 \mathrm{mg} / \mathrm{kg}$, and placebo, respectively. A total of 10 cases of neoplasm were reported in the cladribine treatment groups compared with no neoplasms reported in the placebo group. Half of the cases reported in the cladribine groups were benign uterine leiomyomas. The other cases were melanoma, pancreatic cancer, ovarian cancer, Stage 0 cervical carcinoma in situ, and choriocarcinoma. Because the reported neoplasms affected many different organ systems, investigators were not able to determine a causal relationship with cladribine. Four deaths were reported during the study and two after the end of the study. The causes of death in the subjects who received cladribine $3.5 \mathrm{mg} / \mathrm{kg}$ were acute myocardial infarction and metastatic pancreatic cancer. The causes of death in the subjects in the $5.25 \mathrm{mg} / \mathrm{kg}$ group were drowning and cardiopulmonary arrest secondary to exacerbation of latent tuberculosis infection. The authors concluded that cladribine may have been responsible for the reactivation of the latter subject's tuberculosis. As a result, tuberculosis screening needs to be completed before initiation of cladribine. When considering reactivation of disease, it should also be noted that 20 patients developed herpes zoster infections. Three patients receiving cladribine had herpes zoster reported as a serious adverse event. A correlation analysis showed that the lowest absolute lymphocyte counts in subjects receiving cladribine were inversely correlated with occurrence of infection (Spearman's correlation coefficient for both cladribine groups combined, $-0.010, P=0.003)$. For the subjects in the placebo group, the causes of death were suicide and hemorrhagic stroke.

The authors concluded that oral cladribine used as a shortterm treatment for RRMS provides a significant benefit in terms of rate of relapse, disability progression, and magnetic resonance imaging measurement of disease activity. It appears that oral cladribine doses of $3.5 \mathrm{mg} / \mathrm{kg}$ and $5.25 \mathrm{mg} / \mathrm{kg}$ are equally efficacious based upon the results of this trial.

\section{Ongoing clinical studies}

An extension study from CLARITY is further evaluating the safety and tolerability of oral cladribine. ${ }^{26}$ The primary outcome being evaluated in this study is safety determined by clinical laboratory testing, electrocardiography, and review of adverse events. Efficacy is being evaluated as a secondary outcome on an annual basis and cumulatively. The projected study completion date is September 2011.

There is currently one other ongoing randomized, doubleblind trial evaluating oral cladribine. The Phase II ONWARD (Cladribine Add-ON to Interferon-beta Therapy in MS Subjects With Active Disease) trial is evaluating the safety, tolerability, and effectiveness of oral cladribine when taken in combination with IFN $\beta .{ }^{27}$ Subjects have been randomized to receive up to four cycles of oral cladribine or matching placebo in combination with IFN $\beta$. The projected study completion date is November 2013.

Another trial evaluating oral cladribine is currently recruiting participants. The ORACLE MS (ORAl CLadribine in Early Multiple Sclerosis) is a Phase III randomized, double-blind trial assessing the efficacy and safety of oral cladribine compared with placebo in subjects with a first clinical demyelinating event at high risk of converting to MS. ${ }^{28}$ Subjects will be randomized to either oral cladribine at $1.75 \mathrm{mg} / \mathrm{kg} /$ year, $3.5 \mathrm{mg} / \mathrm{kg} /$ year, or placebo dosed once weekly for four weeks at the start of the cycle. The projected study completion date is December 2012.

\section{Patient-specific considerations}

Oral cladribine given once daily in short courses may be more appealing to patients than receiving subcutaneous or intramuscular injections indefinitely. Frequent injections can cause anxiety, discomfort, and inconvenience for patients. ${ }^{29}$ The common adverse effects of oral cladribine that occurred in the CLARITY trial included headache, nausea, upper 
respiratory tract infection, and lymphocytopenia. Few patients discontinued therapy as a result of these adverse effects. ${ }^{25}$ Effective, well-tolerated oral treatment for MS could improve long-term adherence and, therefore, help to optimize therapeutic outcomes. ${ }^{16}$ Long-term adverse effects must also be considered when evaluating cladribine and specific patients for its use. One important adverse effect potentially associated with cladribine is infertility. When administered intravenously to monkeys, cladribine has shown suppression of rapidly generating cells, eg, testicular cells. The overall effects of this on fertility are unknown. ${ }^{30}$

\section{Conclusion}

In determining oral cladribine's future place in therapy, it is necessary to consider other emerging oral therapies. Fingolimod is a sphingosine-1-phosphate-receptor modulator. Recently, two studies evaluating oral fingolimod for the treatment of RRMS were published. The FREEDOMS (FTY720 Research Evaluating Effects of Daily Oral therapy in Multiple Sclerosis) study conducted by Kappos et al studied oral fingolimod compared with placebo in adult subjects. ${ }^{31}$ Oral doses of $0.5 \mathrm{mg}$ and $1.25 \mathrm{mg}$ daily were studied. Statistically significant differences were seen with oral fingolimod compared with placebo with regard to annualized relapse rate and risk of disability progression over a two-year time period. For fingolimod $0.5 \mathrm{mg}$ daily, the annualized relapse rate was 0.18 . For fingolimod $1.25 \mathrm{mg}$ daily, the annualized rate was 0.16 . This is compared with an annualized relapse rate of 0.40 for placebo $(P<0.001$ for either dose). Both doses of fingolimod reduced the risk of disability progression over a two-year period with an HR of 0.70 for $0.5 \mathrm{mg}$ daily and 0.68 for $1.25 \mathrm{mg}$ daily $(P=0.02$ for both doses versus placebo). Oral fingolimod was also studied by Cohen et al in the TRANSFORMS (TRial Assessing injectable interferoN versuS FTY720 Oral in Relapsing-remitting Multiple Sclerosis) study. ${ }^{32}$ In this trial, oral fingolimod, at the same doses of $0.5 \mathrm{mg}$ and $1.25 \mathrm{mg}$ daily, was compared with intramuscular IFN $\beta-1 \mathrm{a}$. A statistically significant reduction in the annualized relapse rate was detected for both doses of oral fingolimod compared with intramuscular IFN $\beta$-1a ( $P<0.001$ for both doses). However, there was no difference in disability progression.

New therapies for the treatment of MS must demonstrate an improvement in the benefit-risk ratio for the current DMTs. ${ }^{33}$ ONWARD and ORACLE MS should provide additional information about oral cladribine. In further defining oral cladribine's place in therapy for RRMS, additional studies will be necessary. Trials evaluating oral cladribine compared with IFN therapy or glatiramer would provide additional insight into its effectiveness. Such studies would also be beneficial in determining if oral cladribine should be considered a first-line agent or a second-line agent, such as natalizumab. In June 2010, Merck filed a New Drug Application with the US Food and Drug Administration for cladribine tablets in the treatment of RRMS. ${ }^{34}$

In the current MS management environment, DMT is limited to injectable therapies. The pharmacokinetic and pharmacodynamic profile of cladribine has made it a theoretic option for short-term oral treatment. The four to six short courses of therapy with two years of benefit seen in the CLARITY study, indicates that short-term treatment has the potential for longterm effects. Combining the theoretic option with promising clinical results from the CLARITY study makes an oral treatment alternative for RRMS closer to reality.

\section{Disclosure}

The authors have no conflicts of interest to report in this work.

\section{References}

1. MS: The Basics. Rocky Mountain MS Center. Available from: http:// www.mscenter.org/education/ms-the-basics/. Accessed Jun 24, 2010.

2. Janiec K, Wajgt A, Kondera-Anasz Z. Effect of immunosuppressive cladribine treatment on serum leucocytes system in two-year clinical trial in patients with chronic progressive multiple sclerosis. Med Sci Monit. 2001;7(1):93-98.

3. Novantrone [Package insert]. Rockland, MA: Serono, Inc; 2009.

4. The IFNB Multiple Sclerosis Study Group. Interferon beta-1b is effective in relapsing-remitting multiple sclerosis. Neurology. 1993;43:655-661.

5. PRISMS Study Group. Randomised double-blind placebo-controlled study of interferon $\beta$-1a in relapsing/remitting multiple sclerosis. Lancet. 1998;352(9139):1498-1504.

6. Jacobs LD, Beck RW, Simon JH, et al. Intramuscular interferon beta-1a therapy initiated during a first demyelinating event in multiple sclerosis. N Engl J Med. 2000;343(13):898-904.

7. Panitch H, Goodin DS, Francis G, et al. Randomized, comparative study of interferon $\beta$-1a treatment regimens in MS. Neurology. 2002;59: 1496-1506.

8. Durelli L, Verdun E, Barbero P, et al. Every-other-day interferon beta-1b versus once-weekly interferon beta-1a for multiple sclerosis: Results of a 2-year prospective randomised multicentre study (INCOMIN). Lancet. 2002;359(9316):1453-1460.

9. Johnson KP, Brooks BR, Cohen JA, et al. Copolymer 1 reduces relapse rate and improves disability in relapsing-remitting multiple sclerosis. Neurology. 1995;45:1268-1276.

10. O'Connor P, Filippi M, Arnason B, et al. $250 \mathrm{mcg}$ or $500 \mathrm{mcg}$ interferon beta- $1 \mathrm{~b}$ versus $20 \mathrm{mg}$ glatiramer acetate in relapsing-remitting multiple sclerosis: A prospective, randomized, multicentre study. Lancet Neurol. 2009;8:889-897.

11. Mikol DD, Barkhof F, Chang P, et al. Comparison of subcutaneous interferon beta-1a with glatiramer acetate in patients with relapsing multiple sclerosis (the REbif vs Glatiramer Acetate in Relapsing MS Disease [REGARD] study): A multicentre, randomised, parallel, open-label trial. Lancet Neurol. 2008;7(10):903-914.

12. Polman CH, O'Connor PW, Havrdova E, et al. A randomized, placebocontrolled trial of natalizumab for relapsing multiple sclerosis. $N$ Engl J Med. 2006;354(9):899-910.

13. Rudick RA, Stuart WH, Calabresi PA, et al. Natalizumab plus interferon beta-1a for relapsing multiple sclerosis. $N$ Engl J Med. 2006;354:911-923. 
14. Tysabri [Package insert]. Cambridge, MA: Biogen, Inc; 2009.

15. Rio J, Nos $C$, Tintore $M$, et al. Defining the response to interferon- $\beta$ in relapsing-remitting multiple sclerosis patients. Ann Neurol. 2006; 59(2):344-352.

16. Leist TP, Vermersch P. The potential role for cladribine in the treatment of multiple sclerosis: Clinical experience and development of an oral tablet formulation. Curr Med Res Opin. 2007;23(11):2667-2676.

17. Sipe JC. Cladribine for multiple sclerosis: Review and current status. Expert Rev Neurother. 2005;5(6):721-727.

18. Beutler E. Cladribine (2-chlorodeoxyadenosine). Lancet. 1992;340(8825): 952-956.

19. Kopadze T, Dobert M, Leussink VI, Dehmel T, Kieseier BC. Cladribine impedes in vitro migration of mononuclear cells: A possible implication for treating multiple sclerosis. Eur J Neurol. 2009;16(3):409-412.

20. Liliemark J, Juliusson G. On the pharmacokinetics of 2-chloro-2'deoxyadenosine in humans. Cancer Res. 1991;51(20):5570-5572.

21. Liliemark J. The clinical pharmacokinetics of cladribine. Clin Pharmacokinet. 1997;32(2):120-131.

22. Kearns CM, Blakley RL, Santana VM, Crom WR. Pharmacokinetics of cladribine (2-chlorodeoxyadenosine) in children with acute leukemia. Cancer Res. 1994;54(5):1235-1239.

23. Liliemark J, Albertioni F, Hassan M, Juliusson G. On the bioavailability of oral and subcutaneous 2-chloro-2'-deoxyadenosine in humans: Alternative routes of administration. J Clin Oncol. 1992;10(10): 1514-1518.

24. Albertioni F, Juliusson G, Liliemark J. On the bioavailability of 2-chloro2'-deoxyadenosine (CdA). The influence of food and omeprazole. Eur J Clin Pharmacol. 1993;44(6):579-582.
25. Giovannoni G, Comi G, Cook S, et al. A placebo-controlled trial of oral cladribine for relapsing multiple sclerosis. $N$ Engl J Med. 2010;362(5): 416-426.

26. Clarity extension study. Available from: http://www.clinicaltrials.gov/ ct2/show/NCT00641537. Accessed Jul 22, 2010.

27. Phase II cladribine add-on to interferon-beta (IFN-b) therapy in MS subjects with active disease (ONWARD). Available from: http://www. clinicaltrials.gov/ct2/show/NCT00436826. Accessed Apr 1, 2010.

28. Oral cladribine in early multiple sclerosis (MS) (ORACLE MS). Available from: http://www.clinicaltrials.gov/ct2/show/NCT00725985. Accessed Apr 1, 2010.

29. Sipe JC. Cladribine tablets: A potential new short-course annual treatment for relapsing multiple sclerosis. Expert Rev Neurother. 2010;10(3): 365-375.

30. Leustatin [Package insert]. Raritan, NJ: Ortho Biotech Products, L.P.; 2007.

31. Kappos L, Radue EW, O’Connor P, et al. A placebo-controlled trial of oral fingolimod in relapsing multiple sclerosis. $N$ Engl J Med. 2010; 362(5):387-401.

32. Cohen JA, Barkhof F, Comi G, et al. Oral fingolimod or intramuscular interferon for relapsing multiple sclerosis. N Engl J Med. 2010;362(5): $402-415$.

33. Cohen BA, Rieckmann P. Emerging oral therapies for multiple sclerosis. Int J Clin Pract. 2007;61(11):1922-1930.

34. Cladribine (Mylinax). The Multiple Sclerosis Resource Centre. Available from: http://www.msrc.co.uk/index.cfm/fuseaction/show/ pageid/1629. Accessed Jun 29, 2010.
Neuropsychiatric Disease and Treatment

\section{Publish your work in this journal}

Neuropsychiatric Disease and Treatment is an international, peerreviewed journal of clinical therapeutics and pharmacology focusing on concise rapid reporting of clinical or pre-clinical studies on a range of neuropsychiatric and neurological disorders. This journal is indexed on PubMed Central, the 'PsycINFO' database and CAS, and is the official

\section{Dovepress}

journal of The International Neuropsychiatric Association (INA). The manuscript management system is completely online and includes a very quick and fair peer-review system, which is all easy to use. Visit http://www.dovepress.com/testimonials.php to read real quotes from published authors. 